\title{
HOMBRES RECEPTORES DE VIOLENCIA EN EL NOVIAZGO
}

\section{Receptors Men of Dating Violence}

\author{
Karina Pacheco Maldonado* y José Gerardo Castañeda Figueroa**
}

\begin{abstract}
Resumen
Hablar sobre violencia es un tema muy controvertido y lo es aún más cuando se habla de violencia de género y casi siempre se hace referencia a que esta es sólo ejercida hacia la mujer, sin embargo no es así, más bien la violencia ejercida ya sea de un género hacia otro o entre el mismo género. La presente investigación exploró el fenómeno de la violencia en 8 hombres que mantienen una relación de noviazgo, que residen en el Distrito Federal o en la Zona Metropolitana entre 20 y 25 años de edad. Se aplicó la Escala de Autoestima de Rosemberg y una entrevista semiestructurada temática. Identificando algunos elementos de violencia hacia los hombres con más frecuencia en las relaciones de noviazgo. Se observó que los roles y estereotipos de género en la relación de pareja indica que el hombre no tenía permitido llorar y demostrar sus sentimientos; mientras que la mujer no era asociada con el hecho de ser violenta; mientras que en los hechos el hombre pasa a ser receptor y la mujer generadora de violencia.
\end{abstract}

Palabras Claves: Violencia, Género, Sexo

\begin{abstract}
Talking violence is a controversial topic and even more when it talks about gender-based violence. Besides, almost always we refer that this type of violence is only practiced against women, though not, more violence either one genre to another or among the same gender. The present research explored the violence phenomenon in 8 men who have a dating relationship, residing in the Federal District of Mexico or in the Metropolitan Area between 20 and 25 years old. It was applied Rosemberg Self-Esteem Scale and a thematic semi-structured interview. Identifying some violence elements towards men more frequently in dating relationships. It was noted that roles and gender stereotypes in the relationship indicates that man was not allowed to cry and show his feelings; while woman was not associate with being violent, while in fact man passes be receiving and woman generating of violence.
\end{abstract}

Keywords: Violence, gender, sex.

* Docente Universidad Autónoma Metropolitana Unidad Iztapalapa. k_pacheco_m@hotmail.com

** Docente Universidad Autónoma Metropolitana Unidad Iztapalapa. jgcafi@hotmail.com 


\section{INTRODUCCIÓN}

Un tema de gran interés dentro de la Psicología Social es la violencia como forma de comportamiento social debido a que condiciona y permite la modificación de comportamientos, dado a que no somos individuos aislados, sino que nos encontramos en estructuras sociales y grupos específicos que permiten desarrollar: valores, expectativas, roles y status.

La violencia en México hoy en día es un tema de gran relevancia debido a los cambios de la modernidad dentro de las sociedades, es por esto, que se debe de hablar de violencia hacia los hombres; esto debido a que en la sociedad en la que vivimos, a los hombres les esta negado demostrar sus sentimientos y debilidades, debido a que se convierten en blancos de burla y aún más, que un hombre llore debido a que es catalogado como un "maricón", "puñal", "niña" entre otros términos. Por el contrario a las mujeres le está permitido socialmente demostrar sus sentimientos amorosos y su ternura expresarlos; es por ello que en la mayoría de las ocasiones para los hombres no es tan fácil decir que su pareja los violenta.

La Organización Mundial de la Salud (OMS) define la violencia como el uso deliberado de la fuerza física o el poder, ya sea en grado de amenaza o acción, contra uno mismo, otra persona o un grupo o comunidad que cause o tenga muchas posibilidades de causar lesiones, muerte, daños psicológicos, trastornos del desarrollo o prohibiciones (OMS, 2002).

En este sentido (Lammoglia, 2004) menciona que en las relaciones de pareja en ocasiones se presentan noviazgos violentos en los cuales se van expresando manifestaciones sutiles que suelen pasar inadvertidas. Se inicia con pequeños chantajes, escenas de celos, comentarios mal intencionados, pequeños momentos donde la pareja se convierte en el enemigo, y poco a poco estas agresiones van aumentando.

Aunado a ello, la Encuesta Nacional de Violencia en las Relaciones de Noviazgo (ENVINOV, 2007) detectó que entre los 15 y 24 años hay expresiones de violencia en tres tipos: física, psicológica y sexual.

Es en este contexto que en este artículo se busca aborda un tema poco "visible" y sobre el cual se ha reflexionado escasamente la violencia hacia el hombre en una relación de noviazgo en donde se resaltan algunos factores que intervienen durante el suceso violento, la minimización y naturalización de la violencia; de igual forma la identificación de las formas de violencia ejercida.

\section{GÉNERO, SEXO Y MÁS}

En la construcción social en la que nos encontramos inmersos, se parte de una mirada machista y patriarcal, en donde la sociedad misma se encarga de reproducir y difundir estas conductas violentas; en este sentido que las relaciones de noviazgo se ven afectadas e incluso justificadas en base a la creencia fuertemente difundida y altamente valorada del "verdadero amor".

La violencia no puede ser explicada con mucha facilidad debido a su complejidad pero no por ello debe abandonarse el análisis en sus diversas manifestaciones, las cuales permiten explicar cómo se utiliza en nuestras formas de interacción. Las manifestaciones más comunes son: la violencia física, la violencia psicológica, la violencia estructural, la violencia económica, la violencia social y la violencia sexual.

- La violencia física es la que se ejerce mediante la fuerza en forma de golpes, empujones, patadas y lesiones, mismas que son provocadas con diversos objetos o armas, puede ser rutinaria o cíclica en la cual se combinan momentos de violencia física con periodos de tranquilidad.

Rodríguez (s/f), menciona que el maltrato físico se detecta por la presencia de hematomas, heridas, quemaduras, fracturas, dislocaciones, cortes, pinchazos entre otras.

- La violencia psicológica se denomina también como verbal o psicológica (emocional) y se ejerce mediante insultos, blasfemias, crueldad mental, gritos, desprecio, exclusión, intolerancia, humillación, discriminación, castigos o amenazas. Rodríguez (s/f), indica que es un tipo de violencia que no deja rastro físicos, sin embargo puede provocar importantes efectos psicológicos; son conocidos, en este sentido, sobre la autopercepción y autoestima, entre los más conocidos. 
- La violencia estructural no es necesariamente individual o interpersonal y son las condiciones sociales a las que son sometidas las persona en virtud de sus posibilidades de acceder a los bienes que la sociedad produce. La violencia estructural tiene como consecuencia que grupos importantes de la sociedad sean excluidos y posiblemente sean percibidos de la misma manera (Valdivieso, Cavieres, \& Antivilo, 2005).

- El Gobierno del Distrito Federal (2005), menciona que la violencia económica puede ser el control del flujo de recursos monetarios o bienes materiales con los que cuentan las personas, pero en ocasiones son obligados a entregar sus ingresos al agresor, y este hace uso exclusivo de los bienes.

- La violencia social que se da dentro de las relaciones de noviazgo son conductas que provocan daño y sufrimiento psicológico tales como: descalificar, criticar a la familia o amigos prohibiéndoles tener convivencia con los demás y en ocasiones dañar o lastimar pertenencias (rompiéndole cosas, desaparecer objetos queridos, lastimar o matar a sus mascotas).

- La Organización Mundial de la Salud (OMS, 2012) menciona que la violencia sexual es cualquier acto sexual, la tentativa de consumar un acto sexual $u$ otro acto dirigido contra una persona mediante coacción por otra persona independientemente de su relación con la víctima, en cualquier ámbito.

Aunado a ello es importante mencionar la diferencia entre Género y Sexo ya que estos dos conceptos hacen referencia a aspectos diferentes aunque comúnmente suelen relacionarlos, asociarlos y hasta confundirlos entre sí.

Hablar del concepto "genero" involucra mencionar el de "sexo" que no son lo mismo, pero para poder comprender uno hay que referirse al otro, por lo que es necesario hacer la distinción de estos dos conceptos.

El "genero" se refiere al aprendizaje que vamos adquiriendo mujeres y hombres, de acuerdo a la cultura y sociedad en que vivimos, asumiendo así roles o patrones de comportamiento, de acuerdo al sexo que tenemos (García, 2001)

Se puede decir que es un conjunto de ideas, creencias y atribuciones sociales que son construidas en cada cultura en un momento histórico, tomando como base la diferencia sexual, y a partir de ellos se construyen los conceptos de masculinidad y feminidad, los cuales determinan el comportamiento, las funciones, oportunidades, valoraciones y las relaciones entre hombres y mujeres. Son construcciones socioculturales que se modifican o adaptan dado que han sido aprendidas.

Money citado en Botello (2008) propuso el término "papel de género" para describir y diferenciar el conjunto de conductas atribuidas a los varones y a las mujeres.

Otro punto es la identidad de género, entendida como la percepción interior de la persona la cual se refleja socialmente en atributos como los roles femenino y masculino.

Roles que se van aprendiendo a través del entorno con el que nos rodeamos, los cuales permiten la construcción de su autopercepción y valorización de acuerdo a su "género".

Por otro lado, el concepto "Sexo" hace referencia a las diferencias y características biológicas, anatómicas, fisiológicas y cromosómicas de los derechos humanos que los definen como hombres y mujeres. Botello (2008) indica que se nace con esas características, y son universales e inmodificables.

Stoller citado en Botello (2008) estableció una diferencia entre "genero" y "sexo", basándose en diversos estudios, en los cuales descubrió que niñas que habían sido educadas de acuerdo a un sexo que fisiológicamente no era el suyo, conservaban un comportamiento referente al del sexo en que habían sido educadas. El sexo hace referencia a las diferencias biológicas naturales entre hombres y mujeres, es decir, a los aparatos reproductores correspondientes. Muchas de esas diferencias son claras y fijas, pero algunas diferencias biológicas pueden variar. Por otro lado el 
género, se construye con base de ideales culturales, sistemas de creencias, imágenes, expectativas sobre la masculinidad y feminidad en cada sociedad.

El instituto Nacional de la Mujer (INMUJER, 2007) menciona que el "género" está determinado por el tiempo o la época y el grupo social, los cuales han llevado a polarizar sus atribuciones y roles sociales, tales como:

Hombres: Cultivo de la razón, Fuerza, Valor, Trabajo, Proveedor.

Mujeres: Cultivo de sentimientos, Abnegación, Debilidad, Ternura, Belleza.

Estas diferencias biológicas, culturales y económicas entre hombre y mujeres, se convirtieron en desigualdades sociales, discriminación e inequidad. Que a la vez son detonantes de la violencia, entendiendo esta como el uso deliberado de la fuerza física o el poder, ya sea en grado de amenaza o acción, contra uno mismo, otra persona o un grupo o comunidad que cause o tenga muchas posibilidades de causar lesiones, muerte, daños psicológicos, trastornos del desarrollo o prohibiciones (OMS, 2002).

Por ello se resaltan los tipos y frecuencias de la violencia que reciben los hombres en la relaciones de noviazgo.

\section{MÉTODO:}

De acuerdo al Instituto Nacional de Estadística y Geografía (INEGI, 2010) el noviazgo constituye una etapa en la cual dos personas establecen una interacción para recrearse o socializarse, es decir tener una compañía, intimidad, sexualidad o la capacidad de elegir un compañero conyugal, además menciona que en el 2009 de los 7.4 millones de habitantes de la capital del país de 12 y mas años el 39.8\% de los jóvenes se encuentran solteros. Aunado a ello en el 2007 destaca que la violencia dirigida hacia los hombres se ha convertido en un problema que va en aumento, las cifras varían de institución a institución pero se puede notar o apreciar que en todas ellas existe un incremento. Es por ello que resulta de gran relevancia, conocer la violencia que reciben los hombres dentro de las relaciones de noviazgo.
Es por esto que el tipo de investigación es cualitativa exploratoria. Debido a que este trabajo pretende conocer los factores psicosociales que intervienen cuando un hombre es receptor de violencia, y para esto se realizó una investigación cualitativa; puesto que esta "concibe la especificidad de las ciencias sociales, aboga, en cambio por el análisis de lo individual y concreto, por medio de la comprensión o interpretación de los significados intersubjetivos de la acción social" (Cea, 2001:44). Además de integrar los resultados que obtuvieron Cienfuegos y Loving (2010) en su investigación sobre, Violencia en la relación de pareja y la investigación de Mendoza (2010) sobre Violencia en las relaciones de pareja de estudiantes jóvenes de nivel superior de IPN.

\section{POBLACIÓN:}

Hombres que viven en el Distrito Federal de México o Zona Metropolitana que tienen una relación de noviazgo

\section{PARTICIPANTES:}

Los participantes fueron hombres entre 20 y 25 años de edad, que se encuentren en una Relación de noviazgo con un mínimo de 4 meses, que vivan en el Distrito Federal o en la Zona Metropolitana.

\section{INSTRUMENTOS}

Fueron utilizados tres tipos de instrumentos: observación sistemática, entrevistas semiestructurada y Test de autoestima de Rosemberg. Utilizandose de la siguiente manera: primero se realizó una observación sistematizada, la cual permitió elaborar la entrevista semi-estructurada, ya que durante ésta se pudo notar varios indicadores de violencia que sobresalían en las parejas Y se aplicó el test de autoestima de Rosemberg para evaluar en nivel de autoestima de las parejas.

\section{PROCEDIMIENTO:}

De acuerdo a la observación realizada se elaboró un guión de entrevista, con intención de que las preguntas fueran dirigidas a encontrar e identificar la violencia que se ejerce hacia el hombre por parte de su novia. 
Se observó por un aproximado de tres semanas y en distintos lugares (cines, parques, universidad, plazas comerciales, transporte público, calle y con amigos), el tipo de convivencia de las parejas; acciones y actos que consideráramos eran indicadores de violencia, basándonos en nuestro protocolo de observación.

Posteriormente se realizó la búsqueda de hombres que cumplieran las características anteriormente mencionadas, esto a través de la técnica "Bola de nieve".

Ya teniendo al sujeto a entrevistar se buscó un espacio (dependiendo el lugar), cómodo, sin muchos distractores, y un ambiente de confianza.

Se realizó una entrevista semi estructurada la cual consta de una sección de preguntas para el perfil sociodemográfico (Este perfil consta de datos generales de los participantes como lo es la edad, la ocupación, con quien vive, con quien tiene más confianza de su familia, edad de la novia, ocupación de la novia, tiempo de relación). Considera siete dimensiones que son la Violencia Física, Económica, Social, Verbal, No verbal, Psicológica y Sexual, dirigiendo las preguntas a identificar los indicadores que se encuentren en cada una de ellas.

Por último se aplicó el Test de autoestima de Rosemberg que es un cuestionario para explorar la autoestima personal entendida como los sentimientos de la valía personal y respeto mismo.

\section{ANÁLISIS \\ Dentro de la interacción de noviazgo en ocasiones es difícil poder identificar la violencia que se recibe por parte de la novia, debido a la naturalización de estas conductas violentas por tal motivo es importante resaltar el tipo de violencia que identificaron los participantes de la investigación e integrar los resultados obtenidos con los que muestran Cienfuegos y Loving (2010) en su investigación sobre, Violencia en la relación de pareja y la investigación de Mendoza (2010) sobre Violencia en las relaciones de pareja de estudiantes jóvenes de nivel superior de IPN.}

A continuación se describen algunos tipos de violencia que se identificaron y enseguida, se ilustra con frases obtenidas de nuestros entrevistados.

\section{La violencia económica}

Se da por medio del sometimiento a través de la disposición de los bienes materiales o del dinero ya sean propios o ajenos, pero generalmente son obligados a entregarle sus ingresos al agresor, haciendo ella uso exclusivo de los mismos (gastando el sueldo de la víctima de forma irresponsable obligando a esta a solicitar ayuda económica a familiares u otros).

Así, cuando los hombres son violentados económicamente por su pareja sentimental, ellas los obligan a trabajar quitándoles sus ingresos y controlando todos sus gastos, mientras ellas saturan las tarjetas de crédito haciendo que ellos paguen.

Por otro lado tanto mujeres y hombres pueden ser receptores de violencia económica, pero cuando los hombres son receptores de violencia económica por parte de su pareja, ellas les piden o exigen que las complazcan en sus caprichos, estos actos ocurren con sutileza, así como cubrir el total o la mayoría de los gastos o pagar las cosas más costosas.

Iván: "Sí, digamos que sí, ella me dice que quiere.

Saúl: "La mayoría de las veces es así de que "me encantó" ,"me gusta demasiado", pasamos una vez y pasamos otra vez, pero no es de que me diga quiero que me compres esto o sí no, no, nos vamos, no nunca".

En este caso los participantes mencionaron que son ellos quienes cubren la mayoría de los gastos cuando salen y sus novias son las que dicen qué quieren, qué se les antoja y que no, les piden lo que les gusta o insinúan lo que quieren para que se los compren les dicen: "me encanto", "me gusta demasiado", "me gustaría tener esto"; para ellos esto no es violencia porque creen que por ser los hombres tienen que ser los proveedores y pagar la mayoría de los gastos o los más costosos, es aquí donde hay una cultura de "machismo" (por así decirlo) que a veces les provoca a ellos el sentirse como los proveedores económicos de la relación.

Sin embargo entre los participantes entrevistados, también hay quien manifiesta que los gastos son repartidos en la pareja esto es no siempre hay una sola persona que cubra los gastos. 
Entrevistador: Cuando salen a pasear o al cine, ¿Quien cubre la mayoría de los gastos?

Juan: "Nos lo repartimos...Tu compra los boletos yo compro las palomitas, no pues está bien".

Entrevistador: ¿Ella te ha pedido que le compres todo lo que se le antoja o quiera?

Juan: "Ella dice que ella es autosuficienciente y no le gusta depender de un hombre, cosa que a mí me ayuda mucho, no nunca me ha dicho cómprame esto cómprame lo otro, ella agarra y ni me dice ya cuando veo ya lo tiene, a mi no me hace sentir mal, no del todo, pero también yo creo se da cuenta en la situación que yo estoy, y apenas no fue, yo creo que hasta a mi me da coraje que me diga eso, más bien que no me diga cómprame esto, cómprame esto; no tiene mucho en el diciembre del año pasado yo le pregunte te gusta este peluche ha si esta bonito, ¿nada mas esta bonito? Y dijo si, y por qué no me lo pides que te lo compre para tu cumpleaños, -hay no como te lo voy a pedir- a mí, digamos que me ofendió, por que digo pues que tan jodido me ve que no puedo comprar un peluche, claro que no,... es la primera vez que yo me siento mal porque no me pide las cosas".

Ahora bien en su estudio de Cienfuegos y Loving (2010) señalan a la utilización de recursos monetarios como medio de control que fomentan la dependencia de la víctima, lo cual se observa también en los resultados obtenidos en esta investigación, con respecto al tema de la violencia económica.

\section{- La violencia verbal}

Este tipo de violencia supone el uso de palabras amenazantes, humillantes, manipuladoras, degradables, para afectar y dañar a la víctima, pretendiendo que crea que es ella la víctima la que está equivocada, exponiéndolo hablando mal de él en público.

Gálvez (2005) menciona que la violencia verbal consiste en amenazas con el suicidio, abandonarlo llevándose a los hijos, quitarle las llaves del coche o casa.

Por lo que en el discurso de los participantes se pudo identificar que en las relaciones con violencia verbal, en la que el hombre es receptor de ella, los indicadores de estas conductas son groserías, gritos e insultos por ejemplo:
Juan: "Ella, sí se exalta y yo soy muy tranquilo, pero nada más eso, grita... ¡Pendejo! o algo asî”... “me empezaba a decir: que payaso, que era bien sentido y que era bien chillón; que no sé cuándo, que era un mandilón, -como me enoja que me diga mandilón-".

Entrevistador: ¿Alguna vez te ha gritado?

Toño: "Habla golpeado, así habla siempre".

Entrevistador: ¿Algún tipo de grosería?

Toño: "Puto"

Entrevistador: ¿Cuándo está molesta?

Toño: "No, a veces por nomas, depende el tono con el que lo haga, eso sí enoja"

La forma de dirigirse a sus parejas generalmente es levantando la voz, en estas relaciones hay reclamos y reproches, le dicen "Pendejo", "Puto", "eres bien sentido y que eres bien chillón" "que era un mandilón", "el chinga ya deja de estar gritando; no mames", "no pero esto", "no pero lo otro", "no es cierto" ¡hey tú! "te pasas, te estás pasando", "eres bien mala onda", ¡ven para acá!", entre otras.

\section{La violencia no verbal}

Son actos corporales de agresión tales como miradas de desprecio, rechazos, indiferencia, silencios, gestos. Son señales que producimos que interpretamos que a menudo provienen del lenguaje verbal. En general cuando se habla de comportamiento no verbal se refiere a señales a las que se ha de atribuir significado. Por ejemplo el movimiento del cuerpo o comportamiento cinésico comprende de modo característico los gestos, los movimientos corporales, los de las extremidades, las manos, la cabeza, los pies y piernas, las expresiones faciales (sonrisa), la conducta de los ojos (parpadeo, dirección y duración de la mirada y dilatación de la pupila), y también la postura (Knapp, 1991).

Entrevistador: ¿Qué caras te hacía?

Juan: Torcía el ceño, torcía la boca, cruzaba los brazos, empezaba mucho a mover el pie, se volteaba a un lado donde que no estuviera yo.

Por el lado de la violencia no verbal, la sufren con miradas de desaprobación, gestos, caras, movimientos corporales, siendo estas muy poco identificables pero sí percibidas y no concientizadas por los hombres. 
Juan: "Un día estaba bien y como que siento que buscaba algo para empezar a discutir y yo agarraba y llegaba y ya ponía sus caras o se alejaba y a mí me molesta, bueno yo siento que era un factor para que empezará la discusión, y ya yo agarraba y le empezaba a decir ¿pues qué tienes? y no pues nada y ya me decía que nada, que nada, nada y ya yo me enojaba y me ponía igual que ella, así súper serio, entonces, ella hacía de cuenta que nunca nos hemos enojado".

Las conductas más frecuentes que realizan las novias son: torcer el ceño, torcer la boca, hacer conejitos (arrugar la nariz), caras de enojadas y serias, miradas de desaprobación, algunos movimientos corporales como cruzar los brazos, dar la espalda, mover el pie, etc., como se muestra en las citas anteriores

La investigación de Cienfuegos y Loving (2010) sobre "violencia en la relación de pareja" presentan conductas verbales y no verbales que tienen como fin atemorizar a la pareja, con la existencia de actos violentos. Esto nos permite confirmar de igual manera con esta investigación que en las relaciones de noviazgo se sufren estos dos tipos de violencia aunque ellos engloban ambas (verbal y no verbal) en nuestro estudio retomamos a cada tipo de violencia por separado.

\section{La Violencia sexual}

Son una serie de experiencias que atentan contra la libertad sexual, a través de actos en los que por medio de la fuerza física, coerción, imposición, criticas, burlas sobre el cuerpo, comparaciones, infidelidad y la celotipia de la pareja. También se presiona a ver fotografía erótica o la pornografía que no queremos ver, así como a ser tocados o a tener relaciones sexuales cuando no queremos o de una manera que nos hace sentir incomodidad" (Givaudan, 2006).

De igual manera tocar a la persona sin su consentimiento u obligarle a que lo toque, realizar prácticas sexuales que no desea, obligarle a tener relaciones de ciertas maneras y en lugares que la agresora determine.

Entrevistador: ¿Has llegado a tener relaciones sexuales sin tener el deseo?

Pepe: "Sí, pero han sido muy pocas ocasiones... Ella llega a la conclusión de decir sabes que si no tienes ganas pues no, pero cuando ya estamos digamos que a la mitad entonces termina todo y así de... ichin que mal! yo quería hacerla sentir bien... Me siento mal por que digo es que no la pude satisfacer, la verdad sí me pone un poco triste".

La frecuencia de la violencia sexual es muy baja en los sujetos entrevistados, al parecer las parejas están muy satisfechas con su vida sexual y llegan a un acuerdo para tener relaciones sexuales.

Entrevistador: Cuando llegan a tener relaciones sexuales. ¿Cómo lo deciden?

Juan: Híjole... yo soy el que tiene toda la iniciativa, es que de hecho no tiene mucho que empezamos nuestra vida sexual, y para empezar, ella, la primera vez que la toque, pues sí se ofendió mucho, pero no me dijo nada, y sí me dijo que ella sentía que la iba a utilizar, y no ... y no fue nada, bueno yo siento, no se ella, fue algo delicado pienso yo y ya después agarre y una vez que en la casa de sus tíos, -ella vive con su tía-, se quedó aquí unos días más, y yo agarre iba a preparar todo, la comida para pasar unos días con ella... y este... me dio una cachetada porque estaba borracha, se puso muy violenta y esta agarra ... como que tenía miedo de que estuviéramos juntos, entonces como que no, como que no, no se decidía ¿no? y le dije no pasa nada... empezamos a tomar los dos y ella como tampoco toma, se le sube así muy rápido, agarro y se puso muy necia muy necia, porque le dije ya no tomes, ya no tomes mucho, porque te vas a marear mucho y te vas a vomitar y entonces agarro y me empezó a cachetear, si me dio como dos cachetadas y así ¿no? se perdió de borracha y ya agarre y la acosté, entonces yo agarre, prendí la tele, ella dormida, ya como a las 7 u 8 ya se despertó con una cruda tremenda y ya le prepare la cena le di de cenar y pues ya dice que no se acuerda, ... me cacheteaste, - ¿te cachetie? no pues como no me acuerdo... no pues como crees... y ya después... -yo me puse a llorar yo como mujer ella como hombre...la primera vez que estuvimos así creo fue más una forma de compensar lo que había hecho...

En este caso no hay violencia sexual, pero se puede manifestarse de diversas formas en el estudio de violencia de Mendoza (2010), quien menciona las frases más usuales que hay en la violencia sexual: 
"Mi novia me obliga a tener un acercamiento sexual con él", "mi novia me presiona para cumplir todas sus fantasías sexuales aunque no me gusten", "mi novia me obliga a tener a tener relaciones sexuales en la forma que ella quiere, pero que a mí me incomodan", "durante la relación sexual, mi novia me pone apodos ofensivos que me molestan", "después de tener un acercamiento sexual con mi novia, ella se porta indiferente", "mi novia se burla de mi cuerpo cuando tenemos encuentros sexuales", "mi novia me obliga a ver pornografía cuando tenemos un encuentro sexual".

De igual manera estos resultados nos hacen ver que en las relaciones de noviazgo hay violencia sexual, la cual antes se pensaba que ocurría sólo cuando ya vivían juntos.

Así Cienfuegos y Loving (2010) en su estudio de violencia en las relaciones de pareja, mencionan, "mi pareja me ha pedido que realice actos sexuales que no deseo", "mi pareja no toma en cuenta mis necesidades sexuales". En su estudio señalan a todas aquellas conductas sexuales que por acción u omisión atentan contra el bienestar de la víctima, como realizar actos sexuales que no desea o no toman en cuenta las necesidades sexuales de la pareja, por lo que la investigación nos permite mencionar que en las relaciones de noviazgo existe violencia sexual y que no es solamente ejercida cuando se encuentra viviendo juntos.

\section{- La violencia social}

Son conductas que provocan daño y sufrimiento psicológico, tales como descalificar, criticar a su familia $\mathrm{o}$ a personas que quiere, aislar a la persona socialmente impidiéndole tener contacto con familiares y amigos o prohibirle tener amistades, ignorarle en público, ser hostil con sus amigos(as), romperle cosas, hacerle desaparecer objetos queridos, lastimar o matar a sus mascotas (Cortés, 2006).

El agresor limita los contactos, aislándolo de su entorno restringiendo las salidas y entradas, tiempos y limitando así un apoyo social importantísimo, en estos casos pretende conocer detalladamente dónde y con quién estuvo, a dónde y con quién va a ir, el tiempo que se va a tardar, revisa celular, correos electrónicos y páginas sociales.
Este tipo de violencia, consta en prohibirles o convencerlos de que no salgan con sus amigos, pero sí con los amigos(as) de ella, dejar de salir o reunirse con sus amigos por ella, prohibirles hablar a ciertas personas (ex-novias), el que ella tenga la mayoría de las veces la última palabra de decidir a dónde salen, así como revisarles el celular (mensajes) o páginas de redes sociales (publicaciones).

Cienfuegos y Loving (2010) señalan en su estudio aquellas conductas que limitan el desarrollo social de la víctima, como prohibiciones de contacto con otra persona. El agresor es quien maneja la relación y todo cuanto pasa en ella debe ser aprobado por él.

Entrevistador: ¿Cómo deciden sus salidas o paseos?

Juan: "Pues realmente no salimos mucho, pero es que a ella no le gusta el cine para empezar, le gusta ir al parque, entonces ella toma el control de donde vamos y donde no, porque ella dice vamos al parque yo con que este con ella pues está muy bien, yo le digo vamos al cine y "hay no, al cine no" y hace miles de caras y miles de largas, luego, luego, luego y a mí si me molesta mucho eso, porque si yo te tengo que consentir, ¿tú por qué a mí no? y yo creo que a las mil o dos mil ya agarra y dice pues si vamos ¿no?, pero ella yo creo es quien decide la mayor parte de donde vamos o no vamos.

De hecho a ella no le gusta salir con mis amigos... yo digo no sabes que vamos con mis amigos y me dice hay no, es que tengo mucha tarea", es que estoy muy cansada, es que me duele la cabeza, y bueno ya agarramos y no vamos, yo termino por no ir, pero cuando ella quiere ir con sus amigas es de "ándale vamos".

Se identifico que cuando salen la mayoría de las veces quién escoge y decide a dónde y cuándo ir son ellas; cuando hay reuniones con los amigos de ellos, ellos han dejado de asistir ya sea porque a ellas no les gusta ir con sus amigos(as) o porque ellas les dicen que no vayan, en cambio cuando ellas tiene relaciones con sus amigas(os), ellas les piden que las acompañen y si no quieres los convencen. 
Les prohíben hablar con ciertas personas (ex novia), les revisan el celular, páginas sociales como Facebook., Twitter, Email.

Uno de los entrevistados a pesar de que su novia lo aleja de ella cuando estaban con su familia, él no considera que esto le cause un daño o que lo haga sentir mal por lo tanto él no lo percibe como violento. Otro caso son las humillaciones, burlas,

Entrevistador: ¿Alguna vez has tenido algún tipo de humillación por parte de ella?

Toño: "Si, con su familia porque te recuerdan cualquier detallito que hiciste mal"

Entrevistador: ¿Ella te ha revisado alguna vez el celular?

Toño: "Sí, siempre lo hace, me incomoda algo".

\section{- Violencia Psicológica}

Ocasiona un grave daño en la esfera emocional que no se nota a simple vista. Por medio de actos que realizan para atacar los sentimientos con la intención de descalificar, desvalorizar, humillar, insultar, criticar, amenazar, chantajear, etc. con el fin de generar temor, terror y control en la pareja, que pretende que la víctima se sienta culpable de todo, aislar a la persona restringiéndole las salidas, haciendolo sentir tonto cuando opina en público. Este tipo de violencia ocasiona una grave disminución a su autoestima, trastornos alimenticios, trastornos del sueño y enfermedades como, gastritis, úlceras, dolor de cabeza y muscular entre otros.

Los participantes entrevistados resaltan en su discurso factores como los celos, el miedo, la indiferencia, la vergüenza y la burla, todos estos actos los hacen sentir mal; también se identificó que los tipos de violencia mencionados anteriormente (verbal, no verbal, física, sexual, económica y social) van ligados a la violencia psicológica.

Los hombres son discriminados por su forma de vestir, peinar, hablar, y esto les ocasiona que se sientan, rechazados por su pareja, y humillados por ella, por lo que se han visto en la necesidad de cambiar sus hábitos y su personalidad para que sean aceptados por la pareja o hasta por la familia de la novia, pero estas frases que los hacen sentir mal son dichas con sutileza es decir, "te quedaría mejor", "te verías mejor " es por eso que los hombres "NO" perciben que son receptores de violencia. Por ejemplo:

Juan: "Ella se pone muy celosa"

Juan: "Ella ya no quería ser mi novia porque me caracterizaba con el físico porque yo era más llenito que ahorita, me vestía muy aseñorado para ella, la forma de peinarme, como que eso hacía que me rechazara cuando me quería acercar a ella, me fue lastimando y me daba mucho coraje obviamente, si me ponía a llorar una que otra vez."

Juan: Ahí me di cuenta que el tipo de chico que le gustaba era distinto a mí, a ella le gustaban con cuerpo bien formado, que vestían a la moda por decir, tuvieran un look o una persona muy propia y pues a mí no me importaba, entonces yo agarre y por coraje o lo que sea agarraba y me metía al gimnasio y comencé a adelgazar, adelgazar y luego me corte el pelo, cambie mi forma de vestir, a lo mejor no muy fashion ¿no?, pero si cambie una que otra ropita y pues así la fui conquistando y pues ya aunque me seguía diciendo que no me quería, ya iba disminuyendo conforme iba cambiando yo.

Juan: Nunca me lo dijo algo como estas gordo o te ves mal siempre me decía no pues te verías mejor así o te quedaría mejor este o yo siento o pienso que esto que otro te quedaría mejor pero nunca me ofendió.

Entrevistador: ¿Alguna vez te ha prohibido hablarle a alguien?

Juan: Sí

Entrevistador: ¿A quién?

Juan: Una ex, ah pues porque se hizo un pleito por Facebook para el colmo ni fue directo y ella no le pareció y i ayi ya ni le hables bloquéala y no sé qué y luego me anda mucho recalcando a otra ni anduvimos ni nada pero me la recalcaba ahí si tú y tu novia fulana tú y tu se van a ir a besar y no sé qué le digo nada que ver nunca anduvimos.

Juan: Es medio burloncita, por todo por errores que hagas palabras que digas mal acciones que hagas mal, que hagas algo que no debes en un lugar donde no se debe y cosas así" 
Los sujetos mencionaron que su novia es muy celosa, que se han avergonzado de ellos, que los han juzgado por el físico, se han burlado de ellos, los han hecho sentir mal.

Además menciona que ellas los han hecho sentir mal publicando frases en sus redes sociales, los hacían llorar, siempre se esperaban a que ellos las buscaran y ellas se hacían del rogar.

Dicen que ya no pueden tener amigas porque ellas son muy celosas, no les puede llegar un mensaje porque les da miedo su reacción de ella.

Job: "Me da temor que me llegue un mensaje cuando estoy con ella"

Aunado a ello existe violencia física versus juegos agresivos dentro de la interacción de sus relaciones de noviazgo, en el uso de la fuerza física, incluye desde los empujones hasta el homicidio este tipo de violencia se ejerce tanto con el cuerpo como con objetos, armas o sustancias

Entrevistador: ¿Te parece que te ha pegado intencionalmente?

Juan: ¿Intencionalmente?, ¿Con el hecho de lastimarme? Pues sí.

En la violencia física, puede incluirse una amplia variedad de comportamientos como pueden ser: agresiones, empujones, rasguños, golpes, fracturas, quemaduras, palizas, bofetadas o hasta homicidios, y se ejercen tanto con el cuerpo como con objetos armas o sustancias, esto con la intención de someter o controlar a su pareja. Este tipo de manifestaciones de la violencia colocan a la víctima en una situación de peligro inminente (Cortés, 2006).

Oscar: "Sí, jugando sí, luego me mordía la cabeza, pero si me dolía... de repente sí me da una nalgada", "A veces de empujar, luego como que boxeo

Rubén: "Si nos hemos golpeado, pero jugando", "Ella me da un zape o me jala el cabello pero es jugando"
La Organización Mundial de la Salud (OMS) clasificó a la violencia física en función de las probabilidades de que causara lesiones. La bofetada y el empujón se definieron como violencia moderada. Y el ser golpeada con el pie, arrastrada o amenazada con un arma, o la utilización de un arma, como violencia grave.

Juan: Jugando y pues este yo creo que es justo y no es justificar... muy de... bueno cuando... me refiero a algo que a ella no le gusta y es cuando me pellizca, me pega, o me avienta, pero siento que es nuestra manera, bueno al menos es mi manera con ella de divertirme, pero ya así de enojada, pues no.

Por otra parte, la violencia física es ejercida hacia ellos con golpes, nalgadas, cachetadas, mordidas, empujones, pellizcos y jalones de cabello; a pesar de que estos actos les han dejado marcas o heridas ellos no se sienten lastimados por lo tanto no son percibidos como conductas violentas y lo justifican con decir que ellas lo hacen jugando, por esta razón es que se agregó a esté concepto de violencia física versus juego agresivos, ya que así es visto, como juegos agresivos. Cienfuegos y Loving (2010) en su estudio de violencia en las relaciones de pareja, incluyen aquellas acciones con las cuales se trata de demostrar que la víctima tiene un estatus menor que el del agresor (humillaciones/ desvalorización); y engloba agresiones que se hacen a otros o frente a otros con el fin de someter a la víctima (chantajes). Estas son las frases más comunes que ellos refieren en relación a todas aquellas conductas en las que por medio de la fuerza el agresor trata de someter a la víctima y la obliga a realizar actos que no desea. "mi pareja me ha amarrado", "mi pareja me ha quemado", "mi pareja me ha golpeado con un palo, cinturón, o algo parecido", "mi pareja me ha sacado de la casa a la fuerza", "mi pareja me ha encerrado", "mi pareja ha intentado ahorcarme o asfixiarme", "mi pareja me ha herido con un objeto o arma", "mi pareja me ha amenazado con matarme", "mi pareja me ha aventado un objeto".

Ahora bien en la investigación sobre violencia en la relación de pareja de estudiantes jóvenes de nivel superior del IPN de Mendoza (2010) arrojó datos de que tanto los hombres como las mujeres sufren violencia y ambos dicen "me pega, pero es jugando"; 
por lo que concuerda con esta investigación donde se observó que este tipo de violencia es tomada como un juego.

Los tipos de violencia en el noviazgo analizados anteriormente han mostrado que existe violencia en el noviazgo, pero para los hombres parece que no existe; ellos lo justifican y/o minimizan con decir:

Pepe: "Son reclamos de ¡ay que no es justo! son reclamos tranquilos"

Saúl: "No la considero violenta como en todo hay peleas, y algunos gritos de los las dos partes pero no la considero violenta, violenta ya sería así que me afectara a mi demasiado o a ella"

Saúl: "Nos decimos cosas de que es que tu vas con fulanito pero me cae gordo pero tengo que aguantar por qué vas con fulanito y ya viene el desquite, no pero es que tu amiga también me cae gorda, pero así no la vamos, pero es cuestión de ¿Cómo se puede decir? pues de cotorreo aunque no sea cierto"

La minimización y/o justificación de la violencia fue un factor encontrado en diversas frases comúnmente por las palabras "pero" o "porque", a manera de minimizar la violencia o en su caso justificar los actos, por ejemplo la mayoría de los entrevistados dicen que los han mordido, pellizcado, cacheteado, celado, etc. pero que es jugando, o que ella así es, y diciendo un por que, a forma de justificar los actos violentos, todas las frases mencionadas anteriormente tienen que ver de cierta manera a que los receptores de violencia menosprecian estos actos y los justifican, de manera consciente o inconscientemente ya que ellos estos actos no son violentos.

Es así como observamos un proceso de naturalización de la violencia en los hombres; esto es, la violencia es vista ya de una manera normal, común, natural. Proceso que conlleva a los participantes para que no perciban toda esa serie de actos como violentos, ya que el jugar agresivamente es normal, el que los celos son comunes, la violencia en las relaciones de pareja es una dinámica usual. Hacen mención de "problemas comunes", "todos somos celosos", "es su manera de divertirse", "la peleas son normales", "se pegan de manera sencilla" en estas frases se observa como la violencia está tan arraigada que ya es parte de nosotros.

\section{Rubén: "Un celo sano"}

Juan: "Uno que otro pellizco pero nada más"

Toño: "Yo siento que es normal,... es como... los dos hemos aprendido de nuestras relaciones pasadas que si han sido violentas..." "Bien no peleamos tan seguido últimamente, pues yo creo que lo normal lo que se podría considerar normal, no llegamos a violencia ni nada asî"

Job: "Lo hacemos de una manera bien sencilla, por ejemplo, luego en su cama nos tiramos, y nos damos de almohadazos y todo eso, pero pues yo lo veo como algo bien tierno ósea así como, rudo no lo veo, entonces si así siempre jugamos".

Oscar: "Si, algunos problemas comunes en las relaciones, como son los celos, falta de tiempo para la otra persona" "Los únicos como medio golpes que nos damos es jugando, es bastante divertido".

Iván: "Yo creo más que nada de, comunes no... como que diferimos"

Rubén: "Creo que todos somos celosos"

Es a partir de los discursos obtenidos de los participantes que se evaluó el nivel de autoestima con el que cuentan.

\section{- Los niveles de autoestima}

Como se puede observar en la tabla todos los entrevistados tienen una autoestima por arriba de los 30 puntos (escala Rosemberg), los cuales indican una autoestima elevada.

En estudios que se han hecho de violencia hacia las mujeres, se ha visto que las mujeres tiene una autoestima baja y en esos casos sí hay una relación (violencia con baja auto-estima), por el contrario en los hombres que sufren violencia no tienen autoestima baja.

Cienfuegos (2008) observó a través de un análisis correlacional, que los hombres y mujeres que experimentan violencia en su relación de pareja suelen presentar mayor sintomatología depresiva 
como sentimiento de culpa y fracaso, dificultad para concentrarse, se sienten insatisfechos, pierden el interés en la gente o bien pierden peso, apetito o tienen insomnio (síntomas físicos). Las mujeres que reportan mayor índice de violencia por parte de su pareja, reportan además de la sintomatología depresiva, síntomas de ansiedad y estados, como preocupación constante por situaciones cotidianas y sentirse alteradas agitadas, nerviosas e irritables.

\section{Tabla. 1 (Escala de autoestima de Rosemberg de los hombres entrevistados)}

\begin{tabular}{cc}
\hline Entrevistado & Puntaje de Autoestima \\
\hline E-1 & 35 \\
E-2 & 39 \\
E-3 & 35 \\
E-4 & 33 \\
E-5 & 35 \\
E-6 & 31 \\
E-7 & 31 \\
E-8 & 38 \\
\hline
\end{tabular}

* Autoestima elevada a partir de los 30 puntos

Al revisar los resultados obtenidos, podemos deducir que conocer el nivel de autoestima con el que cuentan los participantes, no se correlaciona para sufrir violencia o no.

\section{CONCLUSIÓN}

A partir de la información proporcionada por los hombres que participaron en la investigación consideramos que han sido receptores de al menos un tipo de violencia ya sea (verbal, no verbal, física, sexual económica, social y psicológica). Pero la más frecuente es la violencia psicologica, siendo los ocho entrevistados receptores de este tipo de violencia. Conociendo más sobre cada uno de los tipos de violencia se puede decir lo siguiente.

Con Respecto a la violencia verbal se identificó, que el hombre es receptor de este tipo de violencia e indicador de ello son groserias, gritos e insultos.
Por otro lado, la violencia no verbal, se presenta con miradas de desaprobación, gestos, caras, movimientos corporales, siendo éstas muy poco identificables pero sí percibidas y no conscientizadas por los hombres.

Aunado a ello la violencia física es ejercida hacia ellos con golpes, nalgadas, cachetadas, mordidas, empujones, pellizcos y jalones de cabello; a pesar de que estos actos les han dejado marcas o heridas ellos no se sienten lastimados por lo tanto no son distinguidos como violentos y lo justifican con decir que ellas lo hacen jugando, por esta razón es que se agregó a este concepto de violencia, ya que así es visto, como juegos agresivos.

En relación a la violencia sexual, sólo se identificó un caso de los ocho entrevistados en el cual él manifiesta su incomodidad cuando tiene intimidad sin tener el deseo, pero hace un esfuerzo por complacerla lo cual no sucede y le provoca tristeza.

Los hombres que son víctimas de la violencia económica por parte de su pareja, cuando ellas les piden o exigen que las complazcan en comprarles sus caprichos pero con sutileza, así como cubrir el total o la mayoría de los gastos o pagar las cosas más costosas.

La violencia social, consiste en prohibirles o convencerlos de que no salgan con sus propios amigos, pero sí con los amigos(as) de ella, dejar de salir o reunirse con sus propios amigos por ella, prohibirles hablar a ciertas personas (ex-novias), el que ella tenga la mayoría de las veces la última palabra de decidir a dónde salen, así como revisarles el celular (mensajes) o páginas de redes sociales (publicaciones).

En la violencia psicológica, se encontró que los celos son el principal factor para que en la relación comiencen los problemas pero dentro de la violencia psicológica tambien se localizaron mas factores como el miedo, la indiferencia, la vergüenza y la burla, actos que los hacen sentir mal; asimismo se identificó que los otros tipos de violencia mencionados anteriormente (verbal, no verbal, física, sexual, económica y social) van ligados a la violencia psicológica, es decir un tipo de violencia conlleva a otro tipo de violencia. 
Después de identificar los tipos de violencia en la relación de noviazgo y saber que los hombres reciben algun tipo de violencia, se enfoca la mirada a los resultados del nivel de autoestima con el que cuentan, por que la mayoría de los estudios realizados sobre violencia hacia la mujer, marcan como factor importante la autoestima baja que suelen reflejar las víctimas; lo cual en esta investigación muestran lo contrario, se observó que los hombres que sufren violencia no tienen un nivel bajo de autoestima, teniendo un puntaje por arriba de los 30 puntos que Rosenberg señala como una autoestima elevada.

Los actos violentos de los cuales los hombres son receptores se ven tan normales que se naturalizan, como el abuso de poder ya sea de una manera explícita o implícitamente aceptado por las normas o por las costumbres, la violencia se "normaliza" y por lo general permanece ignorada u oculta, a menos que el daño infligido adquiera proporciones excedidas y difíciles de esconder. Su objetivo central es el control y dominio de los otros.

Corsi (2003) menciona que la naturalización es un proceso psicosocial de facilitación de la violencia, el cual obstaculiza detectarla. Es parte de un conjunto de operaciones permisivas que llevan a aceptar los comportamientos violentos como algo "natural", legítimo y pertinente en la vida cotidiana.

El uso de la fuerza es naturalizado hasta tal punto que puede llegar a no ser considerada violencia; como cuando se justifica alguna lesión física recibida por la pareja, en el caso de los entrevistados, hacían mención que estos daños físicos se concebían durante el juego.

Durante el noviazgo la violencia aparece como algo "natural", se llega a legitimar por diversos discursos y desde distintos ángulos, construyendo consensos a su favor.

Por otro lado, el conjunto de operaciones psicológicas tienen como finalidad minimizar, negar, ocultar y justificar los actos de violencia.

La operación psicológica que se encontró en el análisis de los datos fue la minimización, la cual tiende a encubrir los aspectos más duros de la destructividad que está sucediendo. Lo tornan psicológicamente aceptable, no agresivo. Esta operación va en busca del mecanismo de minimización, de empequeñecer los daños que produce la violencia (Corsi, 2003).

Minimizar es hacer que su acto violento parezca menos de lo que en realidad fue; la frase "sólo le di una cachetada", es una forma de aceptar que se le paso la mano, pero no fue gran cosa (Ramírez, 2004), como en las frases recurrentes en esta investigación: "Uno que otro pellizco, pero nada más", "No me decía groserías así muy fuertes", "La cachetada me la dio por que estaba borracha", "Un celo sano", esto es ejemplo de evadir la responsabilidad. Así se define el grado de violencia que puede o no usar, utiliza su propia definición en una forma flexible, define su acto violento como algo sin importancia para no tener que dejar de ser violento (Ramírez, 2004).

Estas operaciones y procesos de minimización y naturalización hace más difícil reconocer la violencia. Esto es algo muy común en las relaciones de noviazgo, ya que la violencia existe en ellas, como en el caso de los entrevistados que se identificó, son receptores pero que no es vista como tal ya que muchos de los actos violentos son vistos como algo normal, común o natural, también se justifican estos actos minimizando el daño. Este efecto podría explicar la imagen positiva de la autoestima en los hombres.

Por lo tanto se puede afirmar que la violencia se ha vuelto bidireccional, sobre todo en las relaciones de pareja, en este caso la relación de noviazgo.

Tanto hombres y mujeres son susceptibles de ser generadores y receptores de violencia, en diversos escenarios; aunque la violencia no es percibida como tal hay indicadores que sirven para mostrar su existencia en las relaciones de noviazgo, por más procesos y operación psicológicas (minimización, justificación, naturalización, etc.) que realicen y sea difícil reconocerla, la violencia está presente.

La violencia es recibida pero no es concebida como tal, ya que se han vuelto dinámicas en las relaciones de noviazgo. 
Se propone hacer un estudio más a profundidad, de tipo cualitativo, que explore el ámbito familiar, para conocer si existen patrones dentro de su hogar que repercuta en la relación y así se propicie violencia.

\section{LOS SUPUESTOS DE INVESTIGACIÓN}

En una relación de noviazgo el hombre también sufre violencia. De hecho los ocho entrevistados mencionaron sufrir violencia, por lo menos cinco de los ocho tipos de violencia. Los hombres sufren violencia en una relación de noviazgo, aun cuando existe una seria dificultad para identificarle como tal ésta es referido más bien como parte de un "juego".

La violencia psicológica es la que más se ejerce hacia los hombres, los ocho entrevistados sufren este tipo de violencia. Esto corrobora al supuesto: El tipo de violencia que recurrentemente ejercen las mujeres hacia los hombres, es la psicológica. Este tipo de violencia es muy difícil de identificar; los hombres que sufren este tipo de violencia no lo pueden decir abiertamente porque no les creen y los señalan como "maricones, chillones o mandilones" Ciertamente los ocho entrevistado sufren violencia psicológica como: que se avergüencen de ellos, los rechacen, les reprochen, pero sobre todo, los celos es uno de los principales factores psicosocial, y existiendo la violencia bidireccional en el noviazgo, tanto hombres como mujeres sufren y ejercen violencia, el hombre puede ejercer un tipo de violencia y recibir el mismo otro tipo de violencia.

Algunos otros supuestos no se corroboraron como que, el hombre que tiene una edad y escolaridad menor a su novia es susceptible de sufrir violencia. Se encontró que la edad no influye para que un hombre sufra o no violencia. De hecho siete de los ocho entrevistados son más grandes de edad que su novia y sufren violencia en su relación por parte de su novia.

Se pensaría que si el hombre tiene un nivel de escolaridad por debajo del de su novia puede ser susceptible a ser violentado, sin embargo, la escolaridad no es un factor para que sufra o no violencia. A pesar de que seis de los ocho los entrevistados estudian un nivel superior igual que su novia.
Se creería que los hombres receptores de violencia tienden a mostrar una autoestima baja. Respecto al test de Rosenberg que se les aplicó, ellos no sufren de baja autoestima a pesar de que sufran violencia, por el contrario tiene una autoestima alta, por más de treinta puntos.

\section{REFERENCIAS:}

Botello, L. L. (2008). Identidad, masculinidad y violencia de género un acercamiento a los varones jóvenes mexicanos. México: Instituto Mexicano de la Juventud.

Cienfuegos, M., Y., I., Arellanez, H., J., L., DíazLoving., R. (2008). Relación entre violencia en las parejas, depresión y ansiedad, y sus diferencias por sexo. Psicología Social en México, XII. México: Amepso.

Cienfuegos, M., Y., I., Díaz- Loving., R. (2010). Violencia en la relación de pareja. Antología psicosocialde laparejaclásicosycontemporáneos. México: Porrúa.

Corsi, J., Peyrú, G., M. (2003). Violencias sociales estudios sobre la violencia. Barcelona: Ariel.

Cortés, A., G. (2006). Pareja y violencia en la violencia nuestra de cada día. México: Plaza y Valdés.

ENVIN, (2007) Encuesta nacional de violencia en las relaciones de noviazgo. Consultada en junio de 2011 en http://www.inegi.org.mx/est/contenidos/ Proyectos/encuestas/hogares/especiales/envin/ Default.asp

García P. (2001) La verdad Sobre la identidad. México: Editorial Paidos

Givaudan, S. P. (2006). Violencia, Como identificar y evitar la violencia en cualquiera de sus formas. México: Wallance.

Gobierno del Distrito Federal (2005). Amores sin violencia programa de prevención y atención d la violencia en las relaciones de noviazgo entre las y los jóvenes de la ciudad de México. México: Instituto de las Mujeres del Distrito Federal. http:// www.inegi.org.mx/est/contenidos/Proyectos/ encuestas/hogares/especiales/envin/Default.asp 
INEGI (2010). Estadística a propósito del 14 de febrero, matrimonios y divorcio en México. Datos del Distrito Federal, México, D.F.

Instituto Nacional de la Mujer. (Noviembre de 2007). Recuperado el Julio de 2011 en http://basica.sep. gob.mx/dgei/pdf/acticultu/ABCGENERO.pdf

Knapp, J., Mark, L. (1991). La comunicación no verbal: el cuerpo y el entorno. México: Paidós.

Lammoglia, E. (2004). El amor no tiene por qué doler, Cómo reconocer una relación destructiva. México: Grijalbo.

Mendoza, P., L. (2010). Violencia en las relaciones de pareja de estudiantes jóvenes de nivel superior de IPN. Instituto Politécnico Nacional, tesis de maestría de Metodología de la ciencia. México: Paidós.
Organización Mundial de la salud (OMS). (2002). Resumen Informe mundial sobre la violencia y la salud. Washinton, D.C.: Organización Panamericana de la Salud para la Organizacion Mundial De la Salud.

Ramírez, H., F., A. (2004) Violencia masculina en el hogar. México: Pax

Rosenberg M, (1965). Society and the adolescent self image. Society of the adolescent self-image. Recuperada en noviembre de 2011 http:// espectroautista.info/tests/emotividad/bienestaremocional/RSES

Valdivieso, P., Cavieres, H., \& Antivilo, A. (2005). La exclusión social: Un estudio psicosocial sobre las percepciones juveniles. En: La Violencia en la Familia, Escuela y Sociedad. Ediciones Universidad Internacional SEK

Fecha de recepción: 15 de setiembre de 2013

Fecha de aceptación: 21 de octubre de 2013 